\title{
Study on Shear Behavior of Concrete-polymer Cement Mortar at Elevated Temperature
}

\author{
Rashid, K. ${ }^{*}$, Ueda, T. ${ }^{2}$ and Zhang, D. ${ }^{3}$
}

\begin{abstract}
In this experimental and analytical work, interfacial shear strengths were evaluated at material and member level. Bi-surface shear strength was performed at material level and three-point bending test was conducted at member level. Beams were strengthened by adding steel reinforcement at soffit level and covered by spraying polymer cement mortar (PCM). After curing, strengthened RC beams were exposed to $60{ }^{\circ} \mathrm{C}$ for 24 hours and tested in three point loading test. Flexural capacity, load deflection relationship and failure modes were observed and compared with the strengthened beams tested at $20^{\circ} \mathrm{C}$. Reduction in flexural capacity was observed with temperature, failure mode was also shifted from flexural mode to debonding mode of failure at elevated temperature. Ultimate shear load and failure modes were predicted by truss analogy approach. Debonding model was proposed by incorporating bi-surface interfacial shear strength, close agreement were observed between experimental and predicted values.
\end{abstract}

Keywords: Bi-Surface interfacial shear strength; debonding model; failure modes; strengthened beams; temperature.

\section{Introduction}

Development of any region is associated with the development of infrastructure. Fully developed countries like Japan, United Arab Emirates, and United States of America, almost have fully developed and durable infrastructure, but due to ageing of infrastructure, deterioration that has taken place must be avoided by annual inspection and maintenance/ repair of damaged part. Strengthening of infrastructure is another demand of current scenario, like converting two lane road to three lane road, making flyovers, bridges, underpasses along with highways etc. Both objectives, repairing and strengthening, are achieved by overlaying of RC structure with various repairing materials, which are widely used in construction industry in the last two decades.

For overlaying, polymer cement mortar (PCM) is widely used due to its superior properties than other cementitious materials. Having better adhesion with concrete, PCM is preferably used for repairing or strengthening [1].

\footnotetext{
${ }^{1}$ Department of Architectural Engineering and Design, University of Engineering and Technology, Lahore-54850, PAKISTAN.

${ }^{2}$ Division of Engineering and Policy for Sustainable Environment, Faculty of Engineering, Hokkaido University, Kita 13 Jo Nishi 8 Chome Kita-ku, Sapporo, JAPAN.

${ }^{3}$ Department of Civil Engineering, College of Civil Engineering and Architecture, Zhejiang University, Hangzhou, CHINA.

*Corresponding author; e-mail: khuram_ae@uet.edu.pk
}

Note: Discussion is expected before November, $1^{\text {st }} 2016$, and will be published in the "Civil Engineering Dimension" volume 19, number 1, March 2017.

Received 15 July 2016; revised 27 August 2016; accepted 31 August 2016.
Adhesion at macro scale was improved by providing adequate rough surface of substrate concrete. Roughness level highly influences the interfacial strengths. Rough surface has bigger surface area for PCM attachment than smooth surface. Hydrodemolition and sand-blasting techniques are considered as the most suitable techniques for roughening the substrate concrete [2].

After proper curing of composite specimens/ structures, they have to be exposed to mechanical loading and various environmental conditions. Stresses are generated, tensile and shear, at interface between concrete and newly overlaid material (PCM) [3]. Interfacial split tensile strength test and bi-surface interfacial shear strength test are commonly used to evaluate the interfacial tensile and shear strengths, respectively [4,5]. Due to interfacial stresses generated at interface, premature debonding failure were commonly reported for composite structures like RC strengthened beams [6-9]. Debonding failure mode is further classified into: intermediate crack debonding (flexural and flexuralshear zone), overlay end debonding, and concrete cover separation. Different models were proposed to predict the debonding mode of failure and respective ultimate load $[6,10,11]$.

Rapid industrialization, non-sustainable development, increase in traffic volume and urbanization are the key parameters that contribute to the increase in temperature level of the region. At many regions of the world, such as Middle East, North America, and some regions of the Subcontinent, 
temperature in summers is already so high, and due to the above mentioned factors temperature may exceed $60^{\circ} \mathrm{C}$ [4]. Increase in temperature level affects the mechanical properties of concrete, PCM, concrete-PCM, and concrete-steel $[4,12]$.

With such background, experiments were designed to evaluate the influence of temperature on strengthened RC beams. Flexural strength, loaddeflection relationship and failure modes were investigated at elevated temperature of $60{ }^{\circ} \mathrm{C}$ and also at control condition of $20{ }^{\circ} \mathrm{C}$. Interface between concrete and PCM were specially prepared for proper adhesion and also improved by adding primer at the interface between concrete and PCM in some cases. Failure load and failure modes were also predicted by using truss analogy approach, debonding criteria was proposed by incorporating interfacial shear strength and verified with experimental observations.

\section{Experimental Description}

\section{Materials and Specimen Preparation}

Ordinary concrete is primary material of ageing infrastructure. Due to deterioration, the mechanical strength might be reduced. By considering this fact, concrete was designed with cubical compressive strength of $30 \mathrm{MPa}$. Ready mix concrete was used in this work. For flexural and shear reinforcement, deformed and plain rebars of diameter 10 and $6 \mathrm{~mm}$ were used, respectively. For strengthening or repairing purpose, polymer cement mortar (PCM) was used. PCM was commercially available and can be bought from local market in China. It was just mixed with designed amount of water at site and sprayed on desired concrete surface. Primer was also used in this work, which was used at interface between concrete and PCM for densification of interface. Primer provides resistance against the penetration of moisture from newly cast overlay material (PCM) to concrete side. Retarder was used to delay the hardening of the concrete. All materials were selected from local market in China.

Compressive strength of concrete and PCM were evaluated by using cubical specimens of 150 and 100 $\mathrm{mm}$, respectively. Composite specimens were also prepared for the evaluation of interfacial shear strength. Ready mixed concrete was poured into wooden mould of size $150 \times 150 \times 100 \mathrm{~mm}$. The bottom surface of concrete specimen of size $150 \times 150$ $\mathrm{mm}$ was treated for roughness. The details are provided in the same section as the preparation of beam specimen. After moist curing of 28 days, concrete specimen was placed in the $150 \mathrm{~mm}$ cubical mould, where treated surface was exposed. Primer was applied on the treated surface as the interface of the specimens on half number of specimens. The rest of space was filled with PCM to make $150 \mathrm{~mm}$ cubical specimen (Figure 1). Composite specimens were cured again for 28 days. Seven days were wet curing and twenty one days were dry curing at ambient temperature condition. Wet condition contributes towards hydration of cement in PCM and dry condition provides feasible environment for formation of polymer films [13].

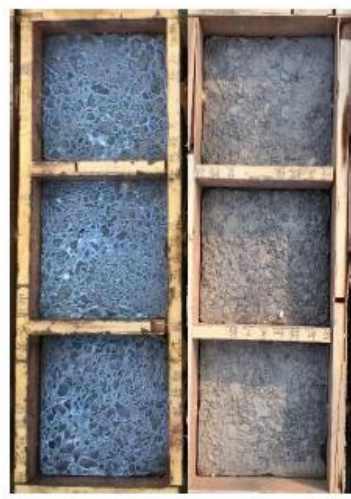

(a)

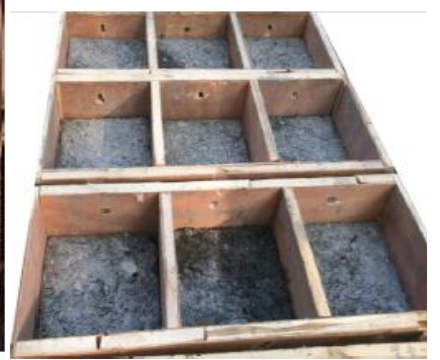

(b)

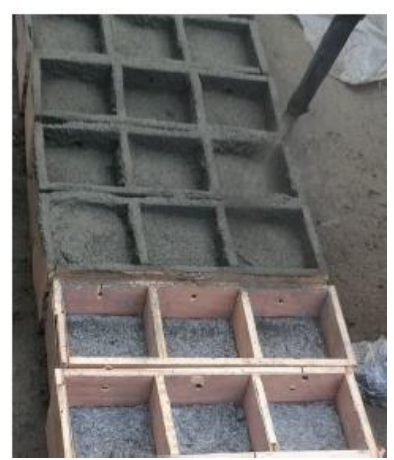

(c)

Figure1. Specimen Preparation for Bi-surface Shear Strength Test. (a) With and Without Primer, (b) $50 \mathrm{~mm}$ Empty Space in the Mould and (c) Spraying of PCM

For preparation of beam specimens, wooden moulds of size 1800 × 150 × 200 mm were prepared. Retarder was mixed with desired amount of water and spread inside bottom of wooden mould. Steel cage was prepared by arranging two deformed bars of $10 \mathrm{~mm}$ in diameter at top and same amount of reinforcement at bottom. Stirrups were prepared by using plain rebar of $6 \mathrm{~mm}$ in diameter and spacing was maintained at distance of $75 \mathrm{~mm}$ center to center through the entire span. Prepared cage was placed in the wooden mould. Spacing of $25 \mathrm{~mm}$ was maintained from all side of the steel cage. Concrete was poured and well compacted and sealed with plastic sheet to avoid evaporation of moisture from concrete. After 36 hours of casting of concrete, bottom plank of mould was the removed and soft layer of concrete was observed due to the presence of retarder. All soft particles, cement paste and mortar, 
was removed by steel wire brush and strong jet of water to get an adequate rough surface. Surface roughness was quantitatively measured and coefficient of roughness (Ra) was $0.73 \mathrm{~mm}$. In previous investigations by authors, sand blasting method for treating substrate concrete surface was adopted and $\mathrm{Ra}$ was 0.37 [8,9]. Three dimensional profile of rough surface is mentioned in Figure 2. After treating bottom surface of all beams, further curing of RC beams were accomplished in wet condition.

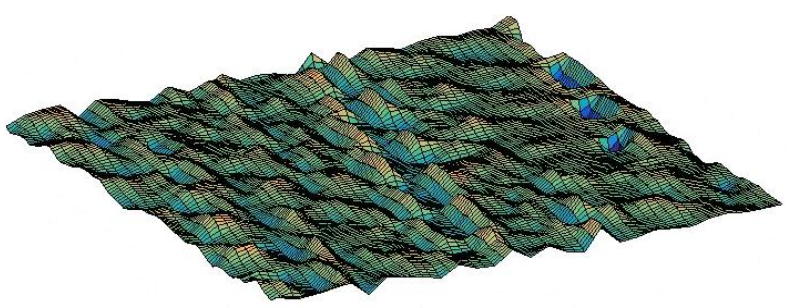

(a)

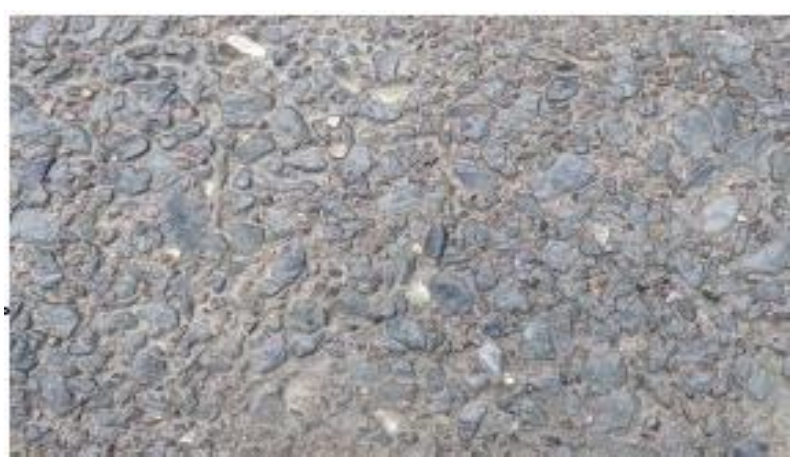

(b)

Figure 2. Profile of Substrate Concrete Surface (a) 3D Evaluation (b) Qualitative Evaluation

For flexural strengthening of RC beams, steel reinforcement were added at the soffit of $\mathrm{RC}$ beam. Three deformed bars were used as flexural reinforcement for strengthening. Spacing between them was maintained by attaching transverse reinforcement of $6 \mathrm{~mm}$ in diameter at spacing of $100 \mathrm{~mm}$ center to center. Before placing steel reinforcement, primer was sprayed on treated surface of substrate concrete of RC beams. Primer was not used in some beams. Mould of size $1280 \times 200 \times 25 \mathrm{~mm}$ were placed on treated surface for cover of added steel reinforcement. PCM was sprayed on newly placed reinforcement up to the height of $25 \mathrm{~mm}$ (Figure 3). Primer was again sprayed on top of the PCM layer to avoid evaporation of moisture from PCM. PCM layer is sealed by thin polythene sheet. Curing of strengthened beams were similarly by wet and dry method.

\section{Bi-Surface Shear Strength Test}

Bond strength in shear can be evaluated by using direct shear test or bi-surface shear strength test.

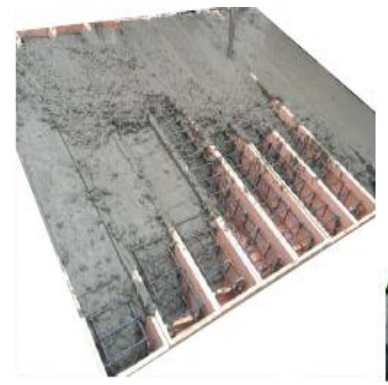

(a)

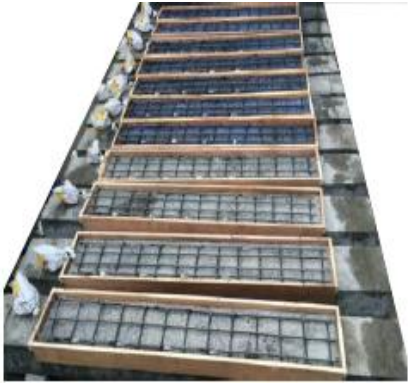

(b)

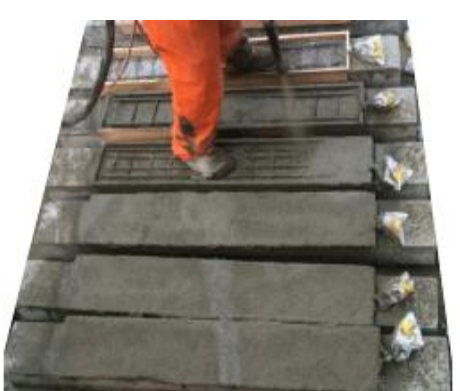

(c)

Figure 3. Specimen Preparation of Overlaid Strengthened RC Beams. (a) Casting of RC Beam, (b) Preparation of Overlaying, (c) Spraying of PCM

The latter test is recommended for evaluation of interfacial strength, having less variation in strengths and chance of error. No special testing arrangement is required [5].

It can be performed by using conventional universal testing machine. Testing set-up and types of specimens, used for the evaluation of interfacial shear strength, is shown in Figure 4. Bi-surface interfacial shear strength can be evaluated by using following Equation (1).

$\tau_{v}=\frac{P_{u}}{2 A}$

where,

$\tau_{v}=$ Interfacial shear strength $(\mathrm{MPa}) ; P_{u}=$ Ultimate $\operatorname{load}(\mathrm{N}) ; A=$ Area of interface $\left(\mathrm{mm}^{2}\right)$

\section{Beam Test}

Strengthened beams were tested in three point loading test. Shear span was $690 \mathrm{~mm}$ and distances of support were $50 \mathrm{~mm}$ away from the overlay end. Four linear variable displacement transducers (LVDT) were used to continuously monitor the displacement during loading. Two LVDTs were aligned with supports and two were aligned at middle of beam. Load was applied manually by hydraulic pump. Load and LVDTs were attached to the data logger and continuously recording the values and saved in computer, which was attached to data logger. Figure 5 presents the geometry, steel reinforcement detail and testing set-up of strengthened RC beam. 


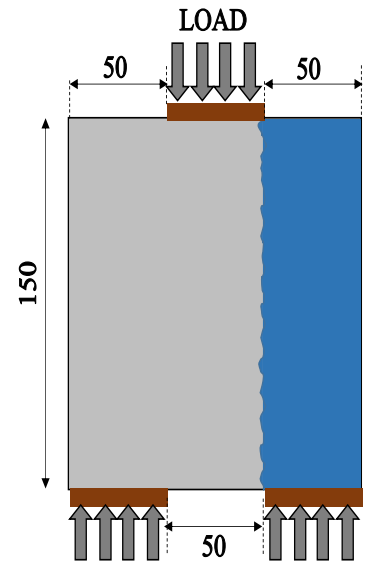

(a)

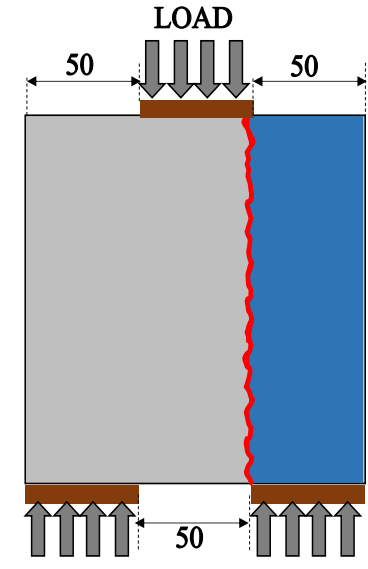

(b)

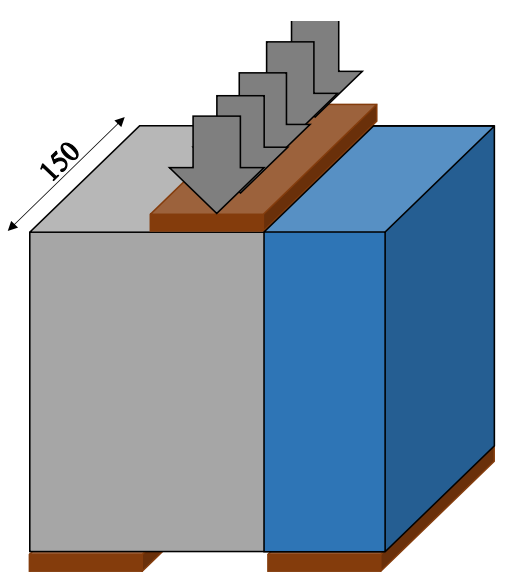

(c)

Figure 4. Type and Testing Set-up of Bi-Surface Shear Strength Test. (a) Without Primer, (b) With Primer, (c) 3D View of Test Setup. All units are in mm.

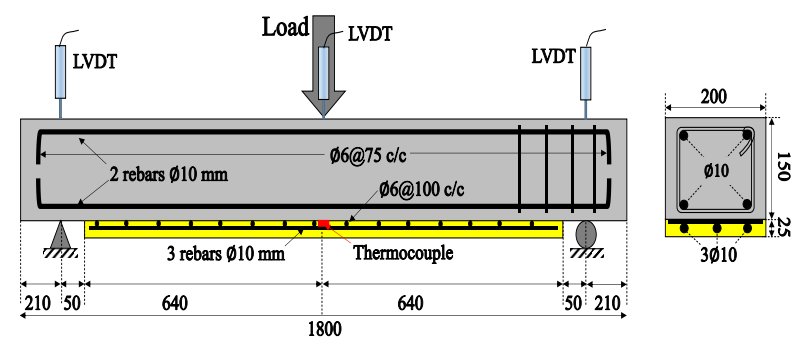

Figure 5. Longitudinal and Cross Sectional Details of Overlay Strengthened RC Beam. All units are in mm.

\section{Exposure Condition}

Due to exposure of RC structures to the severe environmental conditions like elevated environmental temperature, repaired structures also exposed to such conditions after proper curing. So, by considering this fact, strengthened RC beams, after proper designed curing period, were exposed to elevated temperature of $60{ }^{\circ} \mathrm{C}$ with the relative humidity maintained at $60 \%$ for 24 hours. Beams were placed in special designed environmental chamber, where designed temperature level and humidity level was maintained. Testing set-up for beams were also established inside the chamber and beams were tested at designed exposure condition.

Bi-surface shear strength were also conducted at 60 ${ }^{\circ} \mathrm{C}$, composite specimens were put in the oven and transferred to testing machine. Both testing machine and specimens were sealed by insulating layer to resist the temperature lose during transferring and testing. Table 1 presents the types of specimens, tests, and testing condition of the experimentation of this laboratory work.

\section{Experimental Results and Data Discussion}

\section{Bond Strength in Shear}

Bond strength in shear was evaluated by conducting Bi-Surface shear strength test. Figure 6 presents the bond shear strength of both types of composite specimens, with primer (WP) and without using primer at interface (NP), at temperature level of 20 and $60{ }^{\circ} \mathrm{C}$. At $20^{\circ} \mathrm{C}$, composite specimen WP has higher shear strength than NP. Primer contributed to densification of the interface and filled all the voids of porous concrete with polymer film penetrations. Primer also made strong bond with the newly overlaid material (PCM). Strong bond between concrete and PCM was established by primer. Bond was stronger than the aggregate interlocking by hydrated cement paste of mortar. That is why $62 \%$ of concrete was attached to the PCM side after failure, whereas only $40 \%$ aggregate of concrete part was attached to the PCM side after failure, in case of NP specimens [13]. The weakest link is between concrete and PCM, not between aggregate and hydrated cement paste. That is the reason that the shear strength of NP specimen is lower than WP specimen at $20^{\circ} \mathrm{C}$.

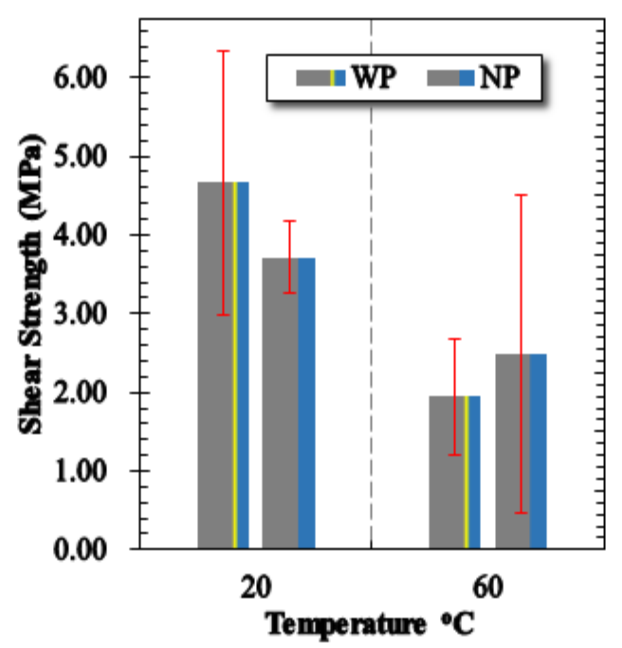

Figure 6. Effect of Temperature on Interfacial Shear Strength 
Table 1. Summary of Specimens, Exposure and Testing Conditions.

\begin{tabular}{|c|c|c|c|c|c|c|c|}
\hline \multirow{2}{*}{ Specimen } & \multirow{2}{*}{$\begin{array}{l}\text { Primer at } \\
\text { interface }\end{array}$} & \multicolumn{2}{|c|}{ Temperature } & \multirow{2}{*}{$\begin{array}{l}\text { Duration } \\
\text { (hours) }\end{array}$} & \multicolumn{2}{|c|}{ Abbreviation } & \multirow{2}{*}{ Test conducted } \\
\hline & & $20^{\circ} \mathrm{C}$ & $60^{\circ} \mathrm{C}$ & & $20^{\circ} \mathrm{C}$ & $60^{\circ} \mathrm{C}$ & \\
\hline \multirow{2}{*}{ Bi-Surface } & Yes & 3 & 3 & 24 & WP-20 & WP-60 & \multirow{2}{*}{$\begin{array}{l}\text { Bi-surface interfacial shear } \\
\text { strength }\end{array}$} \\
\hline & No & 3 & 3 & 24 & NP-20 & NP-60 & \\
\hline \multirow{2}{*}{ Beam } & Yes & 1 & 1 & 24 & WP-20 & WP-60 & \multirow{2}{*}{ Three point loading test } \\
\hline & No & 1 & 2 & 24 & NP-20 & NP-60 & \\
\hline
\end{tabular}

At elevated temperature level of $60^{\circ} \mathrm{C}$, degradation in shear strength was observed (Figure 6). WP specimen degraded more compared to the NP. Fifty eight and 33\% reduction in shear strength was observed of composite specimens type WP and NP, respectively, as compared to $20{ }^{\circ} \mathrm{C}$. For polymers, elevated temperature is considered as the severe condition which damages the polymers significantly $[13,14]$. Primer has significant amount of polymers and that was damaged significantly with the increase in temperature and responsible for the weakening of bond between concrete and PCM. The reduction in strength of composite specimens with increase in temperature was due to the following reasons; (1) degradation in the mechanical properties of PCM $[4,13,14]$, (2) Degradation in the mechanical properties of concrete [15], (3) Increase on porosity of cementations materials with temperature [15], (4) Increase in amount of cement contributes more towards reduction in strength of cementitous material and PCM have higher cement content than ordinary mortar.

\section{Failure Modes of Beam Test}

Strengthened beams were tested in three point loading test at 20 and $60{ }^{\circ} \mathrm{C}$. Expected failure modes of conventional RC beams are; flexural failure, shear failure and flexural and shear failure. For overlaid beams, debonding failure mode was also one of the most commonly reported failure mode $[8,9]$. To predict the debonded load, debonding failure mode was categorized in several types with respect to the position of debonding, such as intermediate crack debonding, overlay end debonding, debonding in flexural and shear zone, and concrete cover separation $[8,9,16]$.

Figure 7 presents the failure modes of tested strengthened $\mathrm{RC}$ beams. At $20{ }^{\circ} \mathrm{C}$, conventional flexural failure was observed for both types of beams, with and without primer. At elevated temperature debonding failure mode was observed as shown in Figure 7(b). Debonding was observed at overlay end and it is magnified in Figure 7(c). Clear separation of concrete and PCM was observed, no exposure of steel reinforcement was observed thus one can confidently say that the failure, is overlaid-end debonded failure, not the concrete cover separation (Figure $7(d))$. It was observed in past studies that higher interfacial stresses were generated at overlay end of strengthened $\mathrm{RC}$ beam $[6,17,18]$. At $20^{\circ} \mathrm{C}$, the interfacial stresses in tension and shear were assumed to be resisted by the composite action of RC beam and overlay. But at elevated temperature, reduction was observed in interfacial shear strength (Figure 6). It was considered that reduction in strength was not capable to resist the interfacial stresses generated at interface and debonding occurred.

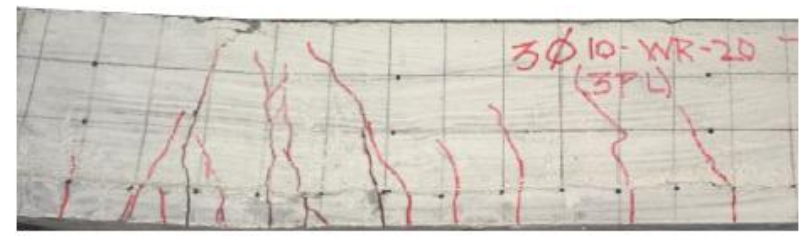

(a) Flexural Failure

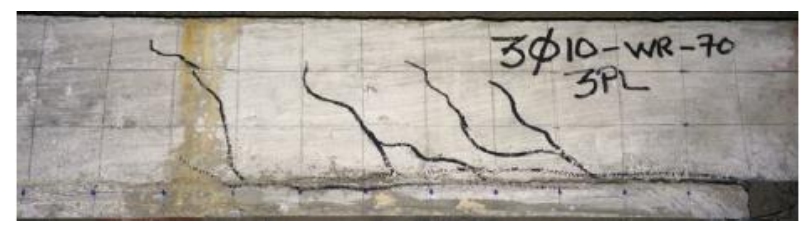

(b) Overlay-end Debonding Failure

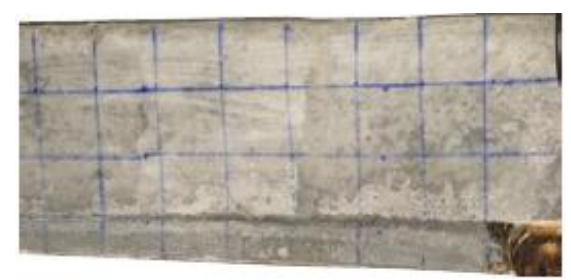

(c) Close-up View of Debonded

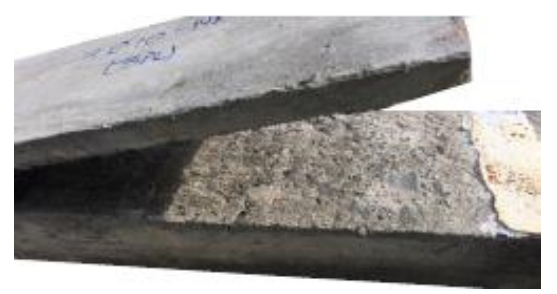

(d) Debonded Surfaces

Figure 7. Failure Modes of Strengthened RC Beams at 20 and $60^{\circ} \mathrm{C}$.

\section{Failure Load of Beams}

Figure 8 presents the failure load of the strengthened beams tested at both temperature levels. At $20^{\circ} \mathrm{C}$, failure load of the overlaid beams with and without primer almost have similar value. Ultimate load of 
overlaid strengthened beams can be calculated by using conventional methods for RC beams [11,16]. At control condition of $20^{\circ} \mathrm{C}$, the effect of primer was negligible and failure modes of both types of beams were conventional flexural failure. At elevated temperature of $60{ }^{\circ} \mathrm{C}$, reduction in the ultimate load was observed as shown in Figure 8. Figure 8 shows 21.11 and $9.18 \%$ reduction in the ultimate load of strengthened beams at elevated temperature, with and without primer, respectively. The reduction in load was due to the debonding mode of failure. Debonding was initiated before the full flexural capacity of overlaid beams [16]. Primer influences the ultimate load of strengthened beams at elevated temperature, interfacial stresses was assumed to be reduced significantly with the degradation of polymers with temperature. Degraded interfacial strengths are not capable of transferring interfacial stresses in tension and shear from overlay to RC part and vice versa. Finally, debonding occurs due to higher concentration of interfacial stresses at cut-off.

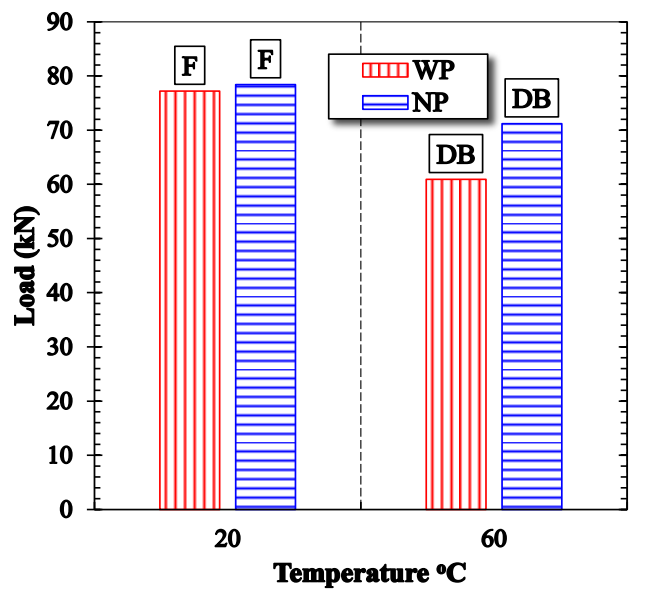

$\mathrm{F}=$ Flexure failure $\mathrm{DB}=$ Debonding failure

Figure 8. Failure Load of Beam Tested at 20 and $60^{\circ} \mathrm{C}$

\section{Load Deflection Relationship}

Figure 9 presents the load deflection relationships of the overlaid strengthened RC beams. At $20^{\circ} \mathrm{C}$, ductile behavior was observed for both cases, with and without primer. After yielding around $70 \mathrm{kN}$, numerous cracks were observed in central region of the beams, length and width of crack increases, deflection of beams also increases significantly with the increase in load. Initial stiffness at both temperature levels is almost similar, and almost similar trend was observed close to the yielding of reinforcement. At elevated temperature, just around yielding of rebars, sudden drop in load was observed due to brittle failure. Maximum deflection of strengthened beams were only $5 \mathrm{~mm}$ at elevated temperature, whereas mid span deflection of overlaid beams were more than $15 \mathrm{~mm}$ at $20^{\circ} \mathrm{C}$. Due to change in curvature of the strengthened beams with loading, higher interfacial stresses generated and change in curvature might be the reason of debonding of the beams. Figure 9 also shows the mode of failure along with the load-deflection relationship. Beams collapsed just around yielding load.

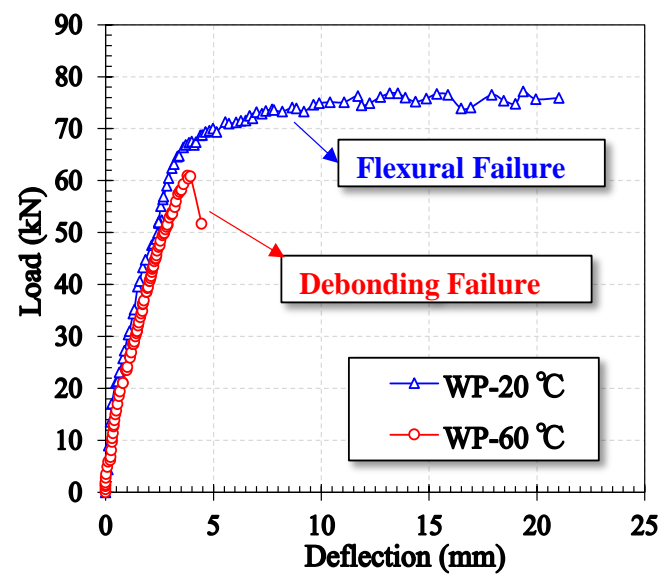

(a) WP- $20^{\circ} \mathrm{C}$

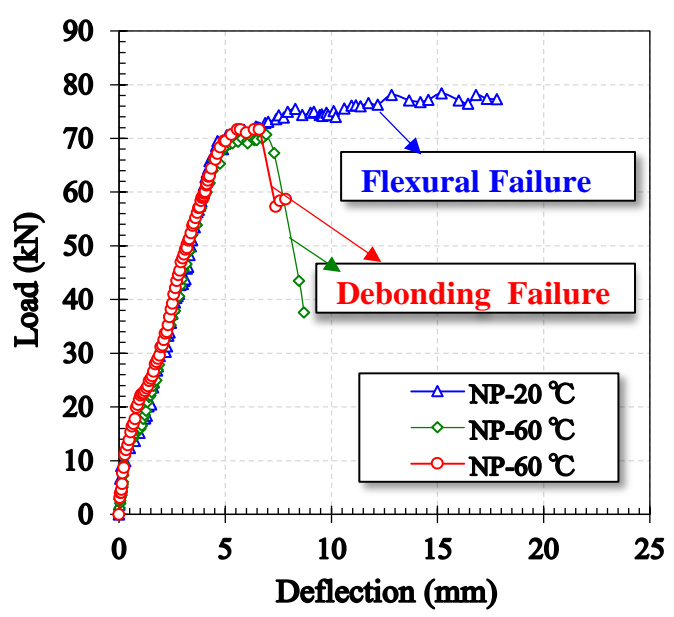

(b) $\mathrm{NP}-60^{\circ} \mathrm{C}$

Figure 9. Load-deflection Relationship of Strengthened Beams

\section{Analytical Discussion}

\section{Truss Analogy Approach}

Truss analogy approach for the analysis of conventional $\mathrm{RC}$ beams were proposed and later modified to use for plated RC beams [10,11]. Truss analogy approach has several advantages like; elasto-plastic behaviour of materials was used instead of linearelastic behaviour. The bond integrity between concrete and newly applied material for load transfer was also incorporated. Figure 10 presents the free body diagram for truss analogy approach. In which, top chords presents the concrete in compression "C" and bottom chord in tension "T" is presented by steel 
reinforcement in concrete and overlay part. Web element presented by shear reinforcement and diagonal concrete struts. Few assumptions were made for plated RC beam and same were considered for overlaid RC beams and rewritten here.

Plastic behaviour of both cementitious materials, concrete, and PCM, were assumed by incorporating effectiveness factor $v$. Its value is commonly used as 0.7 and the same value was assumed in this work $[10,11]$.

Stirrups took the load per unit length and denoted " $\rho_{s s}$ " and presented in Equation (2); where, $A_{t}$ is the tensile area of stirrups, $f_{t y}$ is yield strength of stirrup and $s$ is spacing between stirrups.

$\rho_{s s}=A_{t} f_{t y} / S$

Perfect bond between concrete and PCM was assumed before debonding. Uniform distribution of bonding force $U$ is assumed at ultimate stages. $U$ presents the plane stress flow at concrete-PCM interface.

Stress-free regions were assumed to be near support end and loading point and diagonal compression zone are under such category. Web of concrete is under uniaxial compressive stresses $\sigma_{c}$, which makes an angle $\theta$ with longitudinal axis of beam as shown in Figure 10.

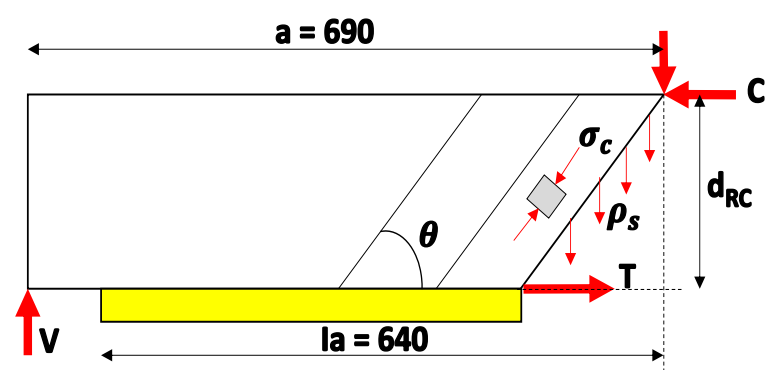

Figure 10. Free Body Diagram of Truss Analogy Approach for Overlaid Beams.

Other advantage of using truss analogy approach is that failure modes were also predicted along with the ultimate shear load. This methodology is capable to predict the flexural and shear failure mode along with other failure modes, viz., flexural failure, shear failure, and debonding failure. Here only flexural failure and debonding failure were observed and only corresponding equations which are capable to predict such modes of failure and corresponding ultimate shear load $V_{u}$ were summarized. For simplification the equations were converted to non-dimensional form by introducing following parameters (Equation (3)) $[10,11]$. Some of notations used in Equation (3) have already been explained and $T_{y}$ is sum of the tensile force in overlay part $\left(A_{s} f_{y}\right)_{O L}$ and concrete part $\left(A_{s} f_{y}\right)_{R C}$.

$\tau_{u}=\frac{V u}{b d} ; \Psi=\frac{\rho s s}{b f c} ; \eta=\frac{T y}{b d f c}$

\section{Flexural Failure}

Overlaid beams can be designed by using conventional methods used for RC beams. Ultimate moment can be obtained accordingly and to predict corresponding shear load for flexural mode of failure Equation (4) was used, which is proposed by Colotti et al. [11].

$\frac{\tau_{u}}{f_{c}}=\frac{M_{u}}{a b d f_{c}}$

where, $M_{u}$ is ultimate moment, $f_{c}$ is modified compressive strength by incorporating effectiveness factor.

\section{Debonding Failure}

From a kinematic point of view, failure is associated with the slippage of concrete-PCM interface in shear span. Slippage is assumed to be increased with the increase in loading and deflection of beam. Slippage is further increased with occurring of minor shear crack (diagonal crack) appears in the flexural shear zone. Prediction of ultimate shear load corresponding to the debonding mode of failure was obtained from Equation (5). Some notations used in Equation (5) have already been explained, whereas debonding strength to stirrup strength is denoted by $\phi$ and is equal to $U_{y} / \rho_{s}$. $U_{y}$ is the ultimate bond strength, $\beta$ is ratio of overlay shear span to depth $\left(I_{d} / d o L\right)$.

$\frac{\tau_{u}}{f_{c}}=\psi\left[\phi+\alpha-\sqrt{(\phi+\alpha)^{2}-2 \phi \beta}, \psi>0\right.$

\section{Ultimate Bond Strength}

For practical design purposes, the yield condition for the concrete-PCM interface has been assumed here as a constant bond strength. Ultimate bond strength or limiting bond strength $U_{y}$ depends upon some factors; like crack spacing and type of debonding failure mode etc. For overlay-end failure, pull-out test was used that was mostly tested for steel and concrete [10-11]. Limiting bond strength by pull-out failure $U_{y 1}$ is given in Equation (6) [11]. The width of overlay boL was $200 \mathrm{~mm}$ and compressive strength of $\mathrm{PCM} f_{c, P C M}$ was $45.35 \mathrm{MPa}$ and $26.96 \mathrm{MPa}$ at 20 and $60^{\circ} \mathrm{C}$, respectively.

$U_{y 1}=b_{O L}\left(2.17+0.02\left(f_{c, p C M}^{\prime}-20\right)\right.$

Another model is proposed here by incorporating interfacial shear strength and the modified shear 
span. In many studies, it was observed that near cutoff, higher concentration of interfacial stresses is generated $[6,16,17]$. Jansze [6] proposed a model in which shear span was modified and modified shear span $B_{\text {mod }}$ was also used by Ahmed to predict the shear behavior of strengthened RC beams [6]. Modified shear span can be obtained by using Equation (7). Effective depth of RC beam $d_{R C}$ was $120 \mathrm{~mm}$ and $\rho_{s}$ is the ratio of area of steel reinforcement and effective area of concrete (Equation (8)). Limiting bond strength $U_{y 2}$ can be obtained by multiplying interfacial shear strength $\tau_{v}, T$ with $B_{\bmod }$ as shown in Equation (9).

$$
\begin{aligned}
& B_{\text {mod }}=\sqrt[4]{\frac{\left(1-\sqrt{\rho_{s}}\right)^{2}}{\rho_{s}} d_{R C}\left(\mathrm{a}-\mathrm{I}_{\mathrm{a}}\right)^{3}} \\
& \rho_{s}=\frac{A_{s}}{b \cdot d_{R C}} \\
& U_{y 2}=\tau_{v_{s} T} B_{\text {mod }}
\end{aligned}
$$

\section{Validation of Model}

Two models were presented in by incorporating pullout strength and interfacial shear strength, which give the limiting bond strength. By using respective bond strengths in Equation (5), ultimate shear load was calculated and corresponding mode of failure must be debonding failure. Final ultimate shear load was calculated as minimum of shear load obtained from Equation (4) and Equation (5) and the respective mode of failure is flexural and debonding, respectively. Table 2 presents the ultimate shear and mode of failure. Analytically, shear load and mode of failure was reported by incorporating limiting bond strength by using pull-out test (Equation (6)) under head of Analytical-PO, and by interfacial shear strength (Equation (6)) under head of Analytical-IS, in Table 2.

To verify the applicability of the proposed models, comparison of experimental observations and analytical results in terms of shear loads and failure modes were made and presented in Figure 11. At 20 ${ }^{\circ} \mathrm{C}$, very close agreement was observed in both conducts, ultimate shear load and failure mode. When compared experimental observations with analytical results and verify the applicability the truss analogy approach for overlaid beams. Influence of primer under flexural failure mode was observed ignorable or negligible at $20^{\circ} \mathrm{C}$. At elevated temperature level

Table 2. Comparison of Experimental and Analytical Ultimate Shear Load and Failure Modes.

\begin{tabular}{ccccccccc}
\hline Beam & $U_{y 1}$ & $U_{y 2}$ & \multicolumn{2}{c}{ Experimental } & \multicolumn{2}{c}{ Analytical-PO } & \multicolumn{2}{c}{ Analytical-IS } \\
\cline { 5 - 9 } Specification & $\mathrm{N} / \mathrm{mm}$ & $\mathrm{N} / \mathrm{mm}$ & $V_{u}(\mathrm{kN})$ & Mode & $V_{u}(\mathrm{kN})$ & Mode & $V_{u}(\mathrm{kN})$ & Mode \\
\hline WP-20 & 535.4 & 808.6 & 38.6 & $\mathrm{~F}^{*}$ & 38.8 & $\mathrm{~F}$ & 38.8 & $\mathrm{~F}$ \\
WP-60 & 461.8 & 337.6 & 30.5 & $\mathrm{DB}^{* *}$ & 36.8 & $\mathrm{DB}$ & 29.1 & $\mathrm{DB}$ \\
NP-20 & 535.4 & 642.4 & 39.2 & $\mathrm{~F}$ & 38.8 & $\mathrm{~F}$ & 38.8 & $\mathrm{~F}$ \\
NP-60 & 461.8 & 429.4 & 35.6 & $\mathrm{DB}$ & 36.8 & $\mathrm{DB}$ & 34.7 & $\mathrm{DB}$ \\
\hline
\end{tabular}

$\mathrm{F}^{*}=$ Flexure failure; $\mathrm{DB}^{* *}=$ Debonding failure

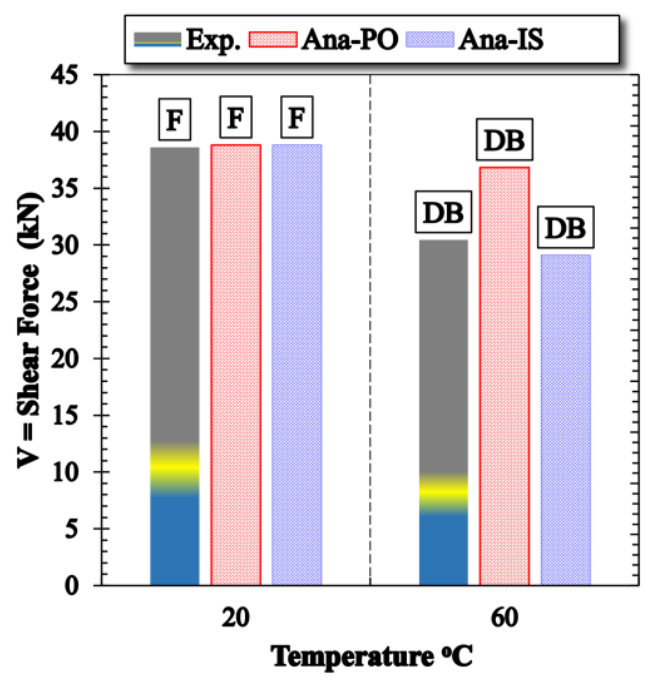

(a) With Primer

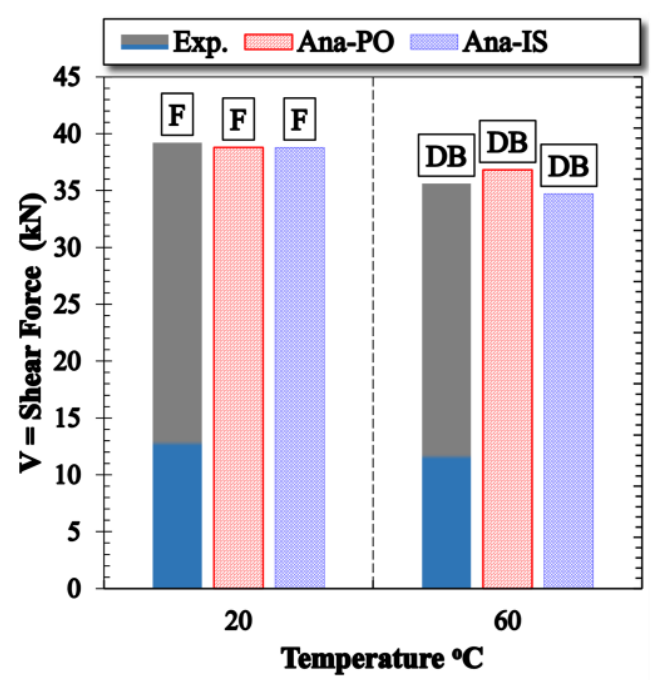

(b) Without primer

$\mathrm{F}=$ Flexure failure; DB = Debonding failure; Exp. = Experimental observations; Ana-IS = analytical-interfacial shear strength; Ana-PO = analytical-pull-out

Figure 11. Comparison of Experimental and Analytical Shear Load and Failure Modes at Elevated Temperature 
of $60{ }^{\circ} \mathrm{C}$, reduction in ultimate shear load was observed and mode of failure also shifted from flexure to debonding mode of failure. Both analytical approaches predict very well the mode of failure. However by using $U_{y 1}$ much difference was observed in ultimate shear load as compared to experimental observation, especially in case of primer (Figure 11(a)). Predicted shear load was $21 \%$ more than the observed values, whereas by using $U_{y 2}$, where influence of primer was incorporated, only $4.5 \%$ reduction in shear load was observed as compared to experimental value. Without using primer at interface (Figure 11(b)), both models predicted shear load very well. Again, predicted value of shear load by using $U_{y 1}$ is more than observed value and it was $3.5 \%$ more than observed value. Although increase in load is small and may be applicable, but due to debonding mode of failure it must be predicted more accurately and predicted value must be less than observed value for safe design purpose. And this objective was accomplished by using $U_{y 2}$, whereby only $2.4 \%$ reduction in shear load was observed as compared to experimental observation, which is considered as more accurate and safe for practical use. However further verification is still needed by using large database of overlaid beams.

\section{Conclusion}

Shear behavior of concrete-PCM was investigated at elevated temperature by conducting experimentation and analytical work. Bond strength in shear was investigated by conducting Bi-Surface shear strength test. For RC members, ultimate shear load and mode of failure was investigated by conducting three point loading test on overlaid RC beams at both temperature level, 20 and $60{ }^{\circ} \mathrm{C}$. Interface quality in both cases, Bi-Surface shear strength and beams, were enhanced by using primer at interface. Comparison were made with respect to temperature and utilization of primer, and following conclusion were extracted;

1. Interfacial shear strength was reduced with the increase in temperature level and the amount of reduction was more when primer was used at interface between concrete and PCM. Failure mode was also shifted from partially adhesive to fully adhesive at elevated temperature with primer.

2. Ultimate shear load of overlaid $\mathrm{RC}$ beam was reduced at $60{ }^{\circ} \mathrm{C}$ as compared to $20^{\circ} \mathrm{C}$. Mode of failure also shifted from flexural to debonding mode of failure with increase in temperature.

3. Influence of primer was negligible at normal temperature condition $\left(20^{\circ} \mathrm{C}\right)$ and clearly seen at elevated temperature in the interfacial shear behavior. The reduction in debonding strength under elevated temperature was greater in case with primer than without primer.
4. Predicted ultimate shear load and mode of failure closely agree with the experimental observations at all temperature levels by limiting bond strength incorporating Bi-Surface interfacial shear strength.

\section{Acknowledgments}

The financial supports from the Grant-in-Aid for Scientific Research (A) of Japan Society of Promotion of Science (No. 26249064), the research fund of Ministry of Transport Construction Technology of China (Nos. 2014318494020) and NEXCO Group Companies' Support Fund to Disaster Prevention Measures on Expressways are greatly appreciated.

\section{References}

1. Fowler, D.W., Polymers in Concrete: A Vision for the 21 $1^{\text {st }}$ Century, Cement and Concrete Composites, 21(5-6), 1999, pp. 449-452.

2. Santos, P.M.D. and Júlio, E.N.B.S., A State-ofthe-art Review on Roughness Quantification Methods for Concrete Surfaces, Construction and Building Materials, 38, 2013, pp. 912-923.

3. Espeche, A.D. and León, J., Estimation of Bond Strength Envelopes for Old-to-new Concrete Interfaces based on a Cylinder Splitting Test, Construction and Building Materials, 25(3), 2011, pp. 1222-1235.

4. Rashid, K., Ueda, T., Zhang, D., Miyaguchi, K., and Nakai, H., Experimental and Analytical Investigations on the Behavior of Interface between Concrete and Polymer Cement Mortar under Hygrothermal Conditions, Construction and Building Materials, 94, 2015, pp. 414-425.

5. Momayez, A., Ehsani, M.R., Ramezanianpour, A.A., and Rajaie, H., Comparison of Methods for Evaluating Bond Strength between Concrete Substrate and Repair Materials, Cement and Concrete Research, 35(4), 2005, pp. 748-757.

6. Smith, S.T. and Teng, J. FRP-strengthened RC Beams I: Review of Debonding Strength Models, Engineering Structures, 24(4), 2002, pp. 385-395.

7. Smith, S.T. and Teng, J., FRP-strengthened RC Beams II: Assessment of Debonding Strength Models, Engineering Structures, 24(4), 2002, pp. 397-417.

8. Zhang, D., Ueda, T., and Furuuchi, H., Intermediate Crack Debonding of Polymer Cement Mortar Overlay-Strengthened RC Beam, Journal of Materials in Civil Engineering, 23(6), 2011, 857-865.

9. Satoh, K. and Kodama, K., Central Peeling Failure Behavior of Polymer Cement Mortar Retrofitting of Reinforced Concrete Beams, Journal of Materials in Civil Engineering, 17(2), 2005, pp. 126-136. 
10. Colotti, V. and Spadea, G., Shear Strength of RC Beams Strengthened with Bonded Steel or FRP Plates, Journal of Structural Engineering, 127(4), 2001, pp. 367-373.

11. Colotti, V., Spadea, G., and Swamy, R.N., Structural Model to Predict the Failure Behavior of Plated Reinforced Concrete Beams, Journal of Composites for Construction, 8(2), 2004, pp. 10422.

12. Rashid, K., Ueda, T., and Zhang, D., Study on Strengthening of RC Beam by Overlaying with Polymer Cement Mortar at Elevated Temperature, Proceeding of Symposium on Reliability of Engineering System, Hangzhou, P.R. China, 2015.

13. Rashid, K., Ueda, T., Zhang, D., and Fujima, S., Study on Behavior of Polymer Cement Mortar in Severe Environmental Conditions, Proceedings of 37th Annual Convention of Japan Concrete Institute (JCI), Chiba, Japan, 2015, pp. 1338-1345.
14. Ohama, Y., Handbook of Polymer-modified Concrete and Mortars Properties and Process Technology, New Jersy: Noyes Publications, 1995.

15. Bazant,Z.P. and Kaplan, M.F., Concrete at High Temperature Material Properties and Mathematical Methods, Harlow: Longman, 1996.

16. Zhang, D., Ueda, T., and Furuuchi, H., Concrete Cover Separation Failure of Overlaystrengthened Reinforced Concrete Beams, Construction and Building Materials, 26(1), 2012, pp. 735-745.

17. Tounsi, A. and Benyoucef, S., Interfacial Stresses in Externally FRP-plated Concrete Beams, International Journal of Adhesion and Adhesives, 27(3), 2007, pp. 207-215.

18. Smith, S.T. and Teng, J., Interfacial Stresses in Plated Beams, Engineering Structures, 23(7), 2001, pp. 857-871. 